I N S T I T U T O

$\mathrm{DE}$

M E D I C I N A

T R O P I C A L

DE

S ÃO PAULO

JOURNAL OF THE SÃO PAULO INSTITUTE OF TROPICAL MEDICINE

${ }^{1}$ Universidade de Pernambuco, Programa de Pós-Graduação em Ciências da Saúde, Recife, Pernambuco, Brazil

2Universidade de Pernambuco, Pronto Socorro Cardiológico de Pernambuco, Ambulatório de Doença de Chagas e Insuficiência Cardíaca, Recife, Pernambuco, Brazil

${ }^{3}$ Universidade de Pernambuco, Faculdade de Enfermagem Nossa Senhora das Graças, Recife, Pernambuco, Brazil

${ }^{4}$ Fundação Oswaldo Cruz, Instituto Aggeu Magalhães, Núcleo de Estatística e Geoprocessamento, Recife, Pernambuco, Brazil

${ }^{5}$ Secretaria Estadual de Saúde de Pernambuco, Programa de Chagas, Recife, Pernambuco, Brazil

${ }^{6}$ Fundação Oswaldo Cruz, Instituto Aggeu Magalhães, Departamento de Parasitologia Recife, Pernambuco, Brazil

Correspondence to: Carolina de Araújo Medeiros

Universidade de Pernambuco, Programa de Pós-Graduação em Ciências da Saúde, R. Arnóbio Marquês, 310, Santo Amaro, CEP 50100-010, Recife, PE, Brazil

Tel: +55 81999413411

E-mail: c.medeirospe @gmail.com

Received: 29 August 2021

Accepted: 2 December 2021

\section{Mapping the morbidity and mortality of Chagas disease in an endemic area in Brazil}

\author{
Carolina de Araújo Medeiros ${ }^{\circledR 1,2,3}$, Maria Beatriz de Araújo Silva ${ }^{\circledR 3}$, André \\ Luiz Sá de Oliveira ${ }^{\circledR 4}$, Sílvia Marinho Martins Alves ${ }^{\circledR 2}$, Maria das Neves \\ Dantas da Silveira Barros ${ }^{{ }^{2}}$, Maria da Glória Aureliano de Melo Cavalcanti ${ }^{\circledR 2}$, \\ Gênova Maria de Azevedo Oliveira ${ }^{\oplus 5}$, Cristina de Fátima Velloso \\ Carrazzone ${ }^{\left({ }^{\circ} 2\right.}$, Wilson Alves de Oliveira Jr. ${ }^{\circledR 2}$, Zulma Maria de Medeiros ${ }^{\left({ }^{1,6}\right.}$
}

\section{ABSTRACT}

Chagas disease is among the 21 neglected diseases according to the World Health Organization. This study aimed to investigate the morbidity and mortality distribution of Chagas disease for identifying areas with greater prevalences and deaths of the disease in Northeast Brazil. A population-based ecological study was performed from 2016 to 2018 using data on acute Chagas disease patients from the Disease Notification Information System, chronic cases from the Chagas Disease and the referral Heart Failure Outpatient Clinic in Pernambuco, and Chagas disease-related mortality from the Mortality Information System. The unit of analysis were Pernambuco State mesoregions. The indicators were spatialized into thematic maps on the occurrence and mortality of the disease per 100,000 inhabitants. No cases of acute disease were reported in the period analyzed. Data on 801 chronic Chagas disease patients were analyzed. The population showed an average age of 62 years, with female predominance. The most prevalent comorbidity was systemic arterial hypertension and cardiologic involvement without ventricular dysfunction. The average chronic disease occurrence rate was 3.2/100,000 people/ year. As for deaths in the mortality system; in total, 350 deaths were recorded, showing male predominance, age $\geq 60$ years, and chronic disease with cardiac involvement as the main mortality cause. The annual average mortality proportion was 1.6/100,000 people. The chronic case distribution showed spatial heterogeneity, with the highest rates of chronic disease and deaths observed in two mesoregions, with the main cause of death being heart-related. This highlights the need for more specialized services in areas with higher burden of the disease to avoid delay in the patients' care.

KEYWORDS: Chagas disease. Morbidity. Mortality. Brazil. Chronic disease.

\section{INTRODUCTION}

Chagas disease is caused by the transmission of Trypanosoma cruzi. The World Health Organization (WHO) estimates that between 6 and 7 million people have Chagas disease, worldwide, crossing the borders of endemic countries, reaching North America, Europe, Oceania and Asia ${ }^{1-3}$.

It is an endemic tropical disease in Latin America, with higher prevalence rates observed in Bolivia, Argentina, Brazil, Mexico and Colombia ${ }^{1,2}$. Brazil has the third largest incidence rate of Chagas disease, with approximately 1.2 million cases and 6,000 deaths per year reported in the last few decades ${ }^{4}$. The Northeast region of the country is among the main endemic regions. The predominant transmission route 
in Brazil is through vectors, except for the Northern region wherein the oral transmission predominates ${ }^{5,6}$.

Triatoma brasiliensis and Triatoma pseudomaculata are the main vectors of Chagas disease in Northeast Brazil, and Pernambuco is among the states in the region with the highest prevalence ${ }^{7}$. In Pernambuco, T. cruzi is transmitted mainly by $T$. brasiliensis, T. pseudomaculata, Panstrongylus megistus and Panstrongylus lutzi, with a significant social impact of Chagas disease in the State ${ }^{7}$. In Brazil, the State Surveillance Program is responsible for the vector control management ${ }^{7}$. However, there is a lack of information on the proportion of infected individuals.

Chagas disease is characterized by an acute and a chronic phase. The acute phase is predominantly asymptomatic, and death occurs in $5 \%$ to $10 \%$ of the symptomatic cases, mainly due to myocarditis or meningoencephalitis ${ }^{8}$. The chronic phase ranges from the indeterminate form to severe forms with cardiac involvement. Clinical classifications consider in addition to the cardiac involvement, digestive or combined impairment (cardiac and digestive) $)^{5,9}$.

Chagas disease is most frequently diagnosed in the chronic phase $^{3,8}$. While acute disease is related to the consumption of foods contaminated by $T$. cruzi and is confirmed by parasite identification, the specific antibody identification is the best diagnostic method for the chronic disease. Immunofluorescence, hemagglutination, and the enzyme-linked immunosorbent assay are the most commonly used serological methods of diagnosis, requiring two positive tests based on different principles for the chronic disease confirmation ${ }^{8,10}$.

Mapping of acute and chronic manifestations of Chagas disease and the associated mortality are important indicators of transmission and constitute a tool for surveillance strategy planning. In this study, we aimed to investigate the morbidity and mortality distribution of Chagas disease for the identification of areas with higher prevalences of disease and more deaths.

\section{MATERIALS AND METHODS}

\section{Study design}

This is a descriptive ecological study, with retrospective and prospective data collection. The study population consisted of Chagas disease cases and deaths from 2016 to 2018 .

\section{Study area}

Pernambuco is a endemic area located in Northeast Brazil; it has a total area of $98,148,323 \mathrm{~km}^{2}$ and an estimated population of 9,557,071 people, as of $2019^{11}$. The State's Human Development Index (HDI) is 0.673, and $12.32 \%$ of its population lives in extreme poverty ${ }^{11}$. Pernambuco has five mesoregions (Recife Metropolitan Region, Zona da Mata, Agreste, Sertao do Sao Francisco, and Sertao) with 184 municipalities, in addition to the State district of Fernando de Noronha (Figure 1).

Recife Metropolitan Region comprises 14 municipalities with an average urbanization rate of $86 \%$ and a HDI of 0.666 . The climate is tropical humid and the predominant biome is the Atlantic Forest ${ }^{11}$.

Zona da Mata mesoregion comprises 43 municipalities and is characterized by an average urbanization rate of $62 \%$, a HDI of 0.6155 , and humid climate; the predominant biome is the Atlantic Forest ${ }^{11}$.

Agreste mesoregion comprises 71 municipalities, with an average urbanization rate of $68 \%$ and a HDI of 0.586 . The climate is humid in areas close to the coast and arid in those close to Sertao. The biome presents a transition from the Atlantic Forest to Caatinga ${ }^{11}$.

Sertao do Sao Francisco mesoregion covers 15 municipalities, with an urbanization rate of $47 \%$. The average HDI of the region is 0.613 with a semiarid climate ${ }^{11}$.

Sertao mesoregion has 41 municipalities, with an urbanization rate of $26 \%$. The HDI in the region is 0.576 . The predominant vegetation is the Caatinga, reflecting the hot and dry climate of the mesoregion ${ }^{11}$.

\section{Study population and variables}

This population-based, ecological study used mesoregions as the unit of analysis. Three information databases were used: Notifiable Diseases Information System (SINAN) for case-series data on acute disease cases; the database of the State referral outpatient clinic for Chagas disease for data on chronic cases; and the Mortality Information System (SIM) for data on the number of deaths from 2016 to 2018. Cases presenting diagnostic errors, duplication, inconsistency, or incompleteness of medical files were excluded.

Data were obtained from the Notifiable Diseases Information System (SINAN), which integrates information on diseases of the Brazilian epidemiological surveillance system $^{12}$. Data were collected from individual records; the notification of acute Chagas disease cases is compulsory in Brazil ${ }^{13}$. Chronic Chagas disease was included in the Brazilian List of Compulsory Notification diseases, injuries and public health events in 2020, but due to the COVID19 pandemic, it has not yet been incorporated by SINAN ${ }^{14}$.

An acute case of Chagas disease is defined by laboratory criteria (patient with positive direct parasitological test with 


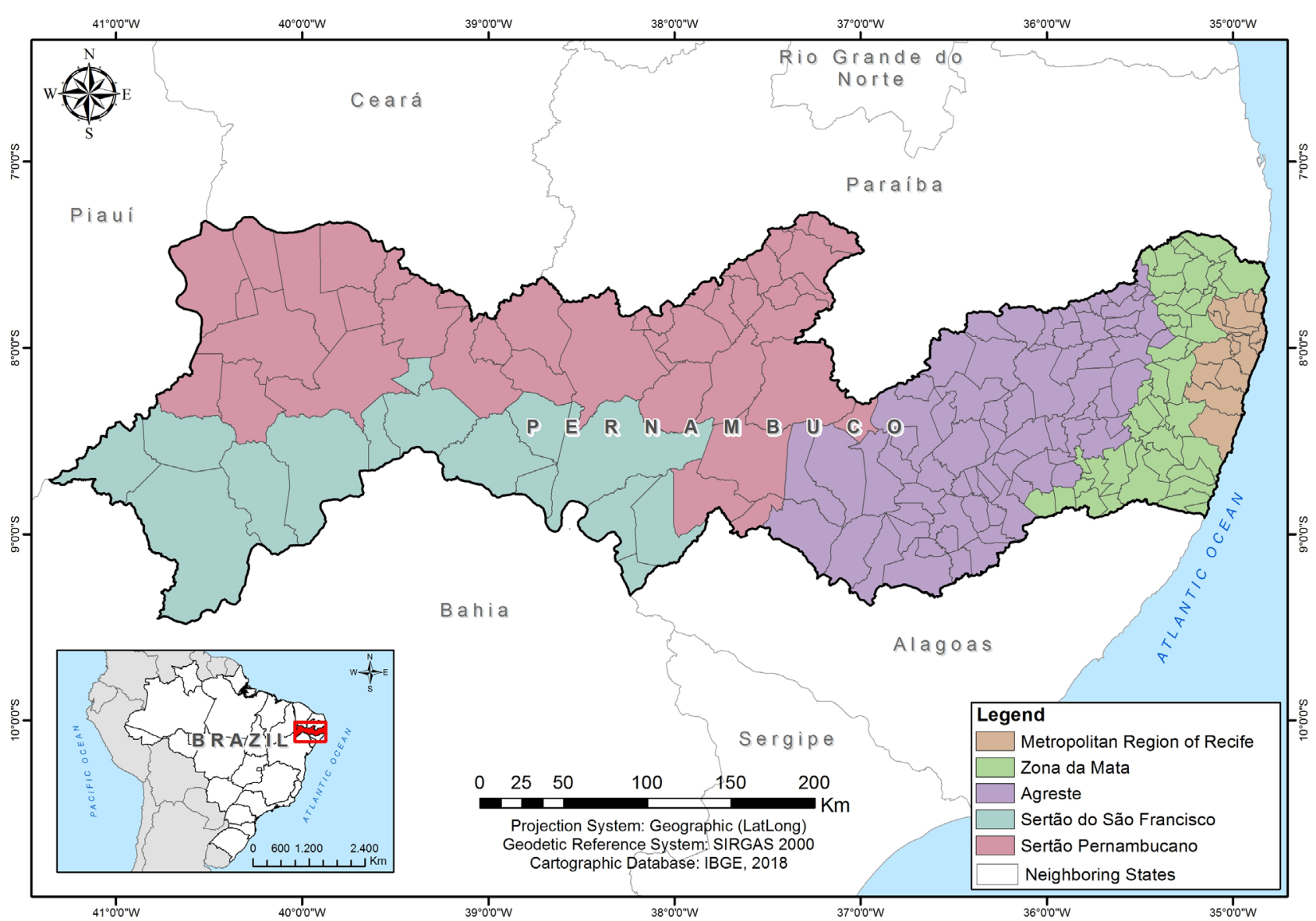

Figure 1 - Geographic location of Pernambuco State and its division into mesoregions.

or without symptoms or positive serology with $T$. cruzi IgM antibodies in peripheral blood; positive detection of anti-T. cruzi IgG antibodies whose concentrations raised at least three titles within a minimum interval of 21 days in paired samples; or positive necroscopic findings), as well as clinical and epidemiological criteria (epidemiological relationship with confirmed cases of acute Chagas disease in disease outbreaks $)^{13}$.

The health care network in the mesoregions of Pernambuco State is composed of basic units, a family health program (primary care), an emergency care unit (UPA) for urgent/emergency care and specialized services. The Chagas Disease Outpatient Clinic of the University of Pernambuco, Recife was established in 1987; it is a reference center in Pernambuco. This outpatient clinic serves patients with suspected and diagnosed chronic Chagas disease. Access to the clinic occurs through referrals from primary health care physicians, clinics, blood centers, and hospitals for family investigation of sick or infected patients with $T$. cruzi, and by spontaneous demand. After confirming the diagnosis of Chagas disease, both symptomatic and asymptomatic patients will undergo a multidisciplinary care ${ }^{15}$. The diagnosis of chronic Chagas diseases cases is confirmed by two different serological tests based on different principles and presenting with concordant results, according to the WHO guidelines ${ }^{16}$.

All enrolled patients were interviewed by a trained team and data on the following parameters were obtained: sex, age, birthplace and residence, ethnicity/self-declared skin colour, level of schooling in years, family income, housing, type of residence in the past and in the present, report on the presence of the vector (Triatominae) in the household, intra or peri-domicile (in the past and at present). Medical records were analyzed for the collection of data on: systemic arterial hypertension, diabetes mellitus, dyslipidaemia, coronary artery disease, clinical manifestations related to Chagas disease, such as electrocardiographic changes and heart failure, and presence of megaoesophagus, megacolon, and stroke. Chronic disease was clinically classified according to the "I Latin American Guidelines for the Diagnosis and Treatment of Chagas' Heart Disease" into: A) indeterminate form, positive serology, normal electrocardiogram, esophagogram, asymptomatic; B1) cardiac form (electrocardiographic or echocardiographic change) without ventricular dysfunction; B2) cardiac form with ventricular dysfunction, without previous or current 
symptoms of heart failure; C) ventricular dysfunction, signs and previous or current symptoms of heart failure, and D) refractory symptoms of heart failure at rest ${ }^{5}$.

Death by Chagas disease was classified according to the following International Classification of Diseases, CID-10 codes: B57) Chagas disease; for the acute forms: B57.0) with heart involvement and B57.1) without heart involvement, and for the chronic forms: B57.2) with cardiac impairment; B57.3) with impairment of the digestive apparatus; B57.4) with nervous system involvement and B57.5) with other organ involvement ${ }^{17}$. Data on sex, age, municipality of residence, and underlying cause of death were collected. Cases from other states, and those with errors in the diagnostic outcome, duplicate records and inconsistencies, and incomplete death certificates were excluded. Population-related data were obtained from the 2010 Demographic Census of the Brazilian Institute of Geography and Statistics (IBGE). The Fernando de Noronha district was excluded from the analysis. The cartographic base of the State's municipalities by mesoregion was adopted in shapefile format in the geographic projection system (latitude/longitude) and SIRGAS 2000 geodetic system, as collected from the IBGE website.

\section{Data management and analysis}

The indicators used, i.e., the occurrence rates of chronic disease and mortality were calculated considering the number of inhabitants (population) per municipality. The occurrence rate of chronic disease was analyzed as an indicator of morbidity and calculated using the number of Chagas disease cases in the municipality by mesoregion in the total period, divided by the estimated population and multiplied by 100,000 inhabitants.

The mortality associated with Chagas disease by municipality in each mesoregion was calculated using the number of deaths due to the disease, as registered in the SIM per municipality in the total period, divided by the estimated population and multiplied by 100,000 inhabitants. Subsequently, for assessing the average annual rate per municipality, the occurrence rate was divided by the analysis period (three years) stratified by interquartile range. Standard deviations on the occurrence rates of chronic disease and mortality were also calculated, identifying areas with values below and above the average and were categorized as equal to or greater than two standard deviations below or above average and equal to one standard deviation below or above the average. The indicators were spatialized using thematic maps of disease occurrence and mortality for the presentation of spatial distributions. A flow map relative to place of birth and area of residence was created using the dominant flow method ${ }^{18}$. The connections were classified based on the method used by Rabbino and Occelli ${ }^{18}$, which evaluates the degree of network interconnections. The connections were divided, according to their intensity, into: low (3 to 4 ), medium (5 to 10) and high (11 to 26). These connections were formed starting with the city of origin (city of birth) ${ }^{11}$ to the place of residence.

Pearson's chi-square tests and Fisher's exact tests were applied for between-group comparisons, with $p \leq 0.05$ indicating statistical significance. The softwares Microsoft Excel 2010 (Microsoft Office, Washington, USA), Statistical Product and Service Solutions (SPSS) version 21.0 (IBM Corporation, Armonk, NY, USA) and QGIS version 3.10 (Open Source Geospatial Foundation, Chicago, USA) were used in the analyses.

\section{Ethics statement}

The study was approved by the Research Ethics Committee of the Hospital Complex HUOC/PROCAPE, Pernambuco (CAAE 88154818.6.0000.5192). This study included information from the database (secondary data) with authorization of the institutions involved; the need of informed consents from the participants was waived.

\section{RESULTS}

A total of 105 cases were investigated by SINAN, with nine cases during the study period (2016 to 2018), but none with acute Chagas disease. After verifying the information contained in the database, the reported cases were classified as discarded due to the absence of clinical or laboratory confirmation of the disease. Overall, 801 chronically infected asymptomatic outpatients (Form A: $182-22.5 \%$ ), classified with the indeterminate chronic form of the disease; with cardiac involvement (Forms B1: 350 or $43.5 \%$, B2: 63 or $8.5 \%$ and C: 206 or $25.5 \%$ ) (Table 1) and patients presenting with cardio-digestive involvement manifested as megaoesophagus and/or megacolon (114 or $14.0 \%)$.

Patients with chronic Chagas disease $(\mathrm{n}=801)$, were predominantly female $(\mathrm{n}=557 ; 69.5 \%)(p<0.001)$ and their average age was $62 \pm 12$ years $(p<0.001)$. In total, $33.0 \%$ of the participants were illiterate, $90.0 \%$ had already lived in a mud house, $71.5 \%$ had lived in a rural house, the average duration of residence in rural areas was 24 years, $81.5 \%$ of the participants reported finding the vector in their residence in the past and $8.0 \%$ reported that the vector was currently present in their residence, and $71.5 \%$ had per capita income of up to one minimum wage $-\mathrm{U} \$ 209(p<0.001)$ 
Table 1 - Socioeconomic, epidemiological and clinical characteristics in relation to the clinical classification of the population with chronic Chagas disease followed up at the referral outpatient clinic $(n=801)$, Pernambuco State, 2016-2018.

\begin{tabular}{|c|c|c|c|c|c|c|}
\hline \multirow{2}{*}{$\begin{array}{l}\text { Variables } \\
\text { Sociodemographic }\end{array}$} & \multicolumn{6}{|c|}{ Clinical Classification } \\
\hline & $A(n=182)$ & $B 1(n=350)$ & $B 2(n=63)$ & $C(n=206)$ & Total $(n=801)$ & $\mathrm{p}$-value \\
\hline \multicolumn{7}{|l|}{ Sex } \\
\hline Female & $140(25.0 \%)$ & $258(46.5 \%)$ & $37(6.5 \%)$ & $122(22.0 \%)$ & $557(100 \%)$ & \\
\hline Male & $42(17.0 \%)$ & $92(38.0 \%)$ & $26(10.5 \%)$ & $84(34.5 \%)$ & $244(100 \%)$ & $<0.001^{b}$ \\
\hline \multicolumn{7}{|l|}{ Age (years) } \\
\hline$<60$ & $101(32.5 \%)$ & $117(37.5 \%)$ & $26(8.5 \%)$ & $66(21.5 \%)$ & $310(100 \%)$ & \\
\hline$\geq 60$ (elderly) & $81(16.5 \%)$ & $233(47.5 \%)$ & $37(7.5 \%)$ & $140(28.5 \%)$ & $491(100 \%)$ & $<0.001^{b}$ \\
\hline \multicolumn{7}{|l|}{ Ethnicity } \\
\hline Mixed & $109(24.5 \%)$ & $181(41.0 \%)$ & $36(8.0 \%)$ & $116(26.5 \%)$ & $442(100 \%)$ & \\
\hline Black & $18(14.5 \%)$ & $59(47.0 \%)$ & $13(10.5 \%)$ & $35(28.0 \%)$ & $125(100 \%)$ & \\
\hline White & $43(23.0 \%)$ & $89(47.0 \%)$ & $13(7.0 \%)$ & $44(23.0 \%)$ & $189(100 \%)$ & \\
\hline Asian & $08(26.5 \%)$ & $14(46.5 \%)$ & $01(3.5 \%)$ & $07(23.5 \%)$ & $30(100 \%)$ & \\
\hline Indigenous & $04(26.5 \%)$ & $07(47.0 \%)$ & $00(0.0 \%)$ & $04(26.5 \%)$ & $15(100 \%)$ & \\
\hline \multicolumn{7}{|l|}{ Schooling level (years) } \\
\hline 0 (illiteracy) & $46(17.5 \%)$ & $118(45.0 \%)$ & $20(7.5 \%)$ & $79(30 \%)$ & $263(100 \%)$ & \\
\hline 1 to 4 & $104(24.0 \%)$ & $186(42.7 \%)$ & $39(9.0 \%)$ & $106(24.3 \%)$ & $435(100 \%)$ & \\
\hline 5- 9 & $1(11.0 \%)$ & $05(55.5 \%)$ & $01(11.0 \%)$ & $02(22.5 \%)$ & $9(100 \%)$ & \\
\hline 10- 12 & $28(31 \%)$ & $39(44 \%)$ & $03(3.5 \%)$ & $19(21.5 \%)$ & $89(100 \%)$ & \\
\hline > 12 (University) & $3(60 \%)$ & $2(40 \%)$ & $0(0.0 \%)$ & $0(0.0 \%)$ & $5(100 \%)$ & \\
\hline \multicolumn{7}{|l|}{ Income (family) / month ${ }^{a}$} \\
\hline Up to 1 minimum wage (U\$ 209) & $109(19 \%)$ & $254(44.5 \%)$ & $51(9.0 \%)$ & $158(27.5 \%)$ & $572(100 \%)$ & \\
\hline Up to 2 minimum wages (U\$ 418) & $27(26.5 \%)$ & $42(41.5 \%)$ & $8(8.0 \%)$ & $24(24 \%)$ & $101(100 \%)$ & \\
\hline$\geq 3$ minimum wages (U\$ 627) & $6(26.0 \%)$ & $6(26.0 \%)$ & $1(4.5 \%)$ & $10(43.5 \%)$ & $23(100 \%)$ & \\
\hline No income & $40(38.0 \%)$ & $48(45.5 \%)$ & $3(3.0 \%)$ & $14(13.5 \%)$ & $105(100 \%)$ & \\
\hline \multicolumn{7}{|l|}{ Current Housing Zone? } \\
\hline Rural & $122(21.5 \%)$ & $254(44.5 \%)$ & $44(7.5 \%)$ & $152(26.5 \%)$ & $572(100 \%)$ & \\
\hline Urban & $60(26.0 \%)$ & $96(42.0 \%)$ & $19(8.5 \%)$ & $54(23.5 \%)$ & $229(100 \%)$ & \\
\hline \multicolumn{7}{|l|}{ Type of Housing in the past } \\
\hline Mud house & $159(22.0 \%)$ & $314(43.5 \%)$ & $57(8.0 \%)$ & $193(26.5 \%)$ & $723(100 \%)$ & \\
\hline Masonry & $23(29.0 \%)$ & $36(47.0 \%)$ & $6(7.0 \%)$ & $13(17.0 \%)$ & $78(100 \%)$ & \\
\hline \multicolumn{7}{|l|}{ Current Housing Type } \\
\hline Mud house & $3(27 \%)$ & $5(46 \%)$ & $0(0.0 \%)$ & $3(27 \%)$ & $11(100 \%)$ & \\
\hline Masonry & $179(22.5 \%)$ & $345(43.5 \%)$ & $63(8.0 \%)$ & $203(26 \%)$ & $790(100 \%)$ & \\
\hline \multicolumn{7}{|c|}{ Report on the presence of the vector (triatomine) in the intra or peri-domicile } \\
\hline \multicolumn{7}{|c|}{ Has the vector been found in your home in the past? } \\
\hline$\overline{\text { No }}$ & $26(17.5 \%)$ & $63(43.0 \%)$ & $13(9.0 \%)$ & $45(30.5 \%)$ & $147(100 \%)$ & \\
\hline Yes & $156(24 \%)$ & $287(44 \%)$ & $50(7.5 \%)$ & $161(24.5 \%)$ & $654(100 \%)$ & \\
\hline \multicolumn{7}{|l|}{ Is the vector still present today? } \\
\hline No & $164(22.5 \%)$ & $323(44.0 \%)$ & $56(7.5 \%)$ & $192(26.0 \%)$ & $735(100 \%)$ & \\
\hline Yes & $18(27.5 \%)$ & $27(41.0 \%)$ & $7(10.5 \%)$ & $14(21.0 \%)$ & $66(100 \%)$ & \\
\hline \multicolumn{7}{|c|}{ Clinical Variables } \\
\hline \multicolumn{7}{|l|}{ Systemic arterial aypertension } \\
\hline Yes & $105(17.5 \%)$ & $268(44.5 \%)$ & $50(8.5 \%)$ & $175(29.5 \%)$ & $598(100 \%)$ & \\
\hline No & $77(38.0 \%)$ & $82(40.5 \%)$ & $13(6.5 \%)$ & $31(15 \%)$ & $203(100 \%)$ & \\
\hline \multicolumn{7}{|l|}{ Diabetes mellitus } \\
\hline Yes & $22(16.5 \%)$ & $64(47.5 \%)$ & $9(6.5 \%)$ & $40(29.5 \%)$ & $135(100 \%)$ & \\
\hline No & $160(24.0 \%)$ & $286(43.0 \%)$ & $54(8.0 \%)$ & $166(25.0 \%)$ & $666(100 \%)$ & \\
\hline \multicolumn{7}{|l|}{ Dyslipidemia } \\
\hline Yes & $79(22.0 \%)$ & $163(45.0 \%)$ & $29(8.0 \%)$ & $91(25.0 \%)$ & $262(100 \%)$ & \\
\hline No & $103(23.5 \%)$ & $187(42.5 \%)$ & $34(7.5 \%)$ & $115(26.5 \%)$ & $439(100 \%)$ & \\
\hline
\end{tabular}


Table 1 - Socioeconomic, epidemiological and clinical characteristics in relation to the clinical classification of the population with chronic Chagas disease followed up at the referral outpatient clinic $(n=801)$, Pernambuco State, 2016-2018. (cont.)

\begin{tabular}{|c|c|c|c|c|c|c|}
\hline \multirow{2}{*}{$\begin{array}{l}\text { Variables } \\
\text { Sociodemographic }\end{array}$} & \multicolumn{6}{|c|}{ Clinical Classification } \\
\hline & $A(n=182)$ & $B 1(n=350)$ & B2 $(n=63)$ & $C(n=206)$ & Total $(n=801)$ & $p$-value \\
\hline \multicolumn{7}{|c|}{ Coronary artery disease } \\
\hline Yes & $2(3.0 \%)$ & $30(45.0 \%)$ & $8(12.0 \%)$ & $27(40.0 \%)$ & $67(100 \%)$ & \\
\hline No & $180(24.5 \%)$ & $320(43.5 \%)$ & $55(7.5 \%)$ & $179(24.5 \%)$ & $734(100 \%)$ & \\
\hline \multicolumn{7}{|l|}{ Stroke } \\
\hline Yes & $9(10.5 \%)$ & $33(38.5 \%)$ & $8(9.0 \%)$ & $36(42.0 \%)$ & $86(100 \%)$ & \\
\hline No & $173(24.0 \%)$ & $317(44.5 \%)$ & $55(7.5 \%)$ & $170(24.0 \%)$ & $715(100 \%)$ & \\
\hline TOTAL & $182(22.5 \%)$ & $350(43.5 \%)$ & $63(8.5 \%)$ & $206(25.5 \%)$ & $801(100 \%)$ & \\
\hline
\end{tabular}

${ }^{\mathrm{a}}$ Family income of 1 minimum wage $(\mathrm{R} \$ 1,045 / \mathrm{R} \$ 1.00$ = average of U $\$ 5.00) ;{ }^{\mathrm{b} p}$-value $0.05 \mathrm{R} \$=$ reais (Brazilian currency).

(Table 1). A high incidence of comorbidities such as systemic arterial hypertension $(p<0.001)$, coronary artery disease $(p<0.001)$, and stroke $(p=0.01)$ was observed. Electrocardiographic changes such as right bundle branch block (RBBB) and left anterior fascicular block (LAFB) were noted in $42.5 \%$ of the participants and heart failure in $26.0 \%$ (Table 1). The most frequently observed clinical classification was B1 (Table 1).

The annual average occurrence rate of chronic Chagas disease was 3.2/ 100,000 people (standard deviation 7.4). Regarding the spatial distribution on the occurrence rate of the disease, the $25 \%$ highest rates were recorded by the interquartile range, considered as $<3.8 / 100,000$ people, with spatial heterogeneity shown in Figure 2. In the analysis of the occurrence rate standard deviations, the municipalities with rates equal to or greater than two standard deviations above the mean were in two mesoregions (Figure 2). The municipality of Sao Benedito do Sul (Zona da Mata) showed the highest rate in this study as an outlier, differing from the other municipalities with high rates.

In terms of the place of origin in chronic cases (Figure 3), the following values were observed: Zona da Mata (39.5\%), Agreste (25.5\%), Sertao (16.0\%), Metropolitan Region (5.0\%), Sertao do Sao Francisco $(0.5 \%)$, and other states $(13.5 \%)$. The corresponding values among those currently residing in each area were: Metropolitan Region (47.5\%), Sertao (14.0\%), Agreste (13.5\%), Zona da Mata $(24.5 \%)$ and Sertao do Sao Francisco $(0.5 \%)$. The flow network comprised 438 connections: 36 low-intensity connections, 18 averageintensity connections, seven high-intensity connections, and 377 with fewer than three connections.

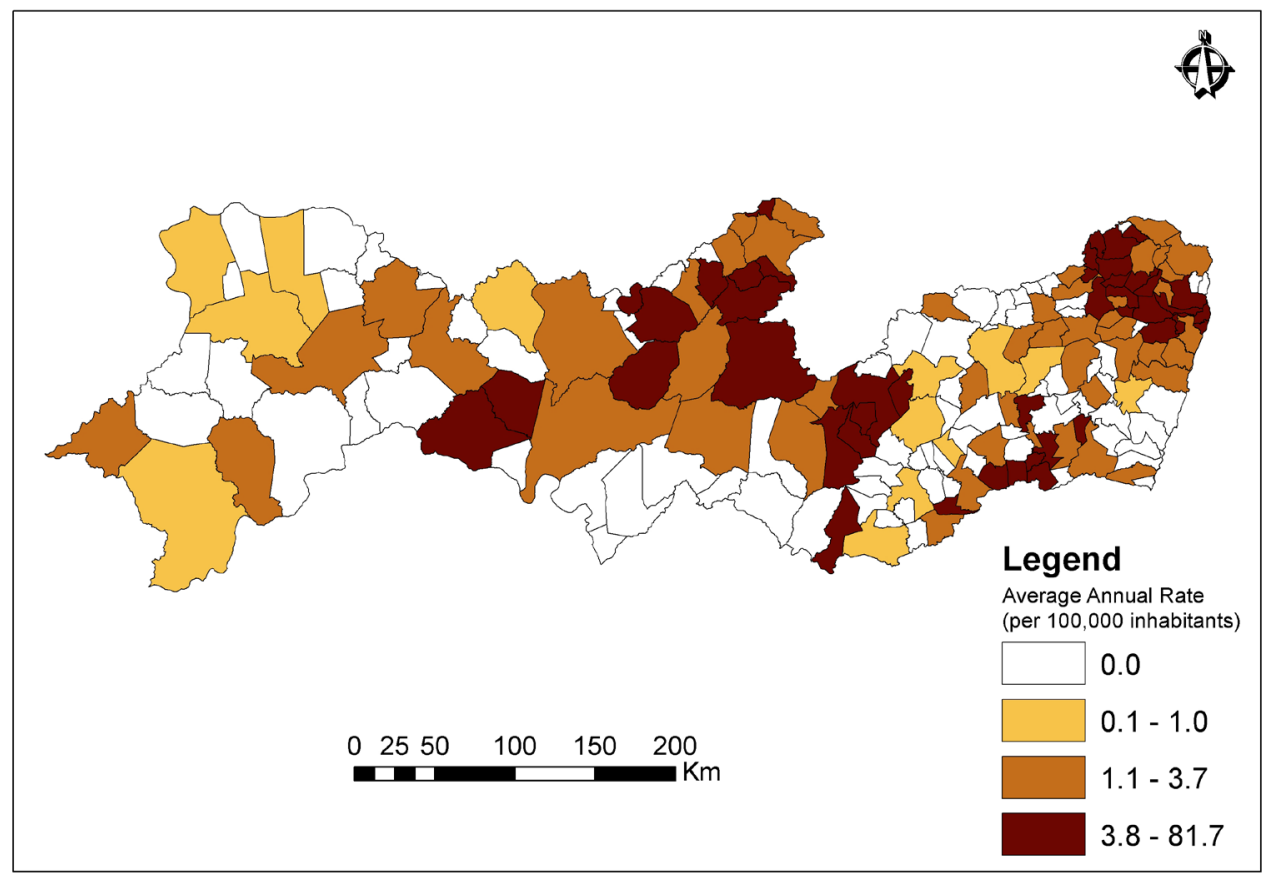

Figure 2 - Map on the average annual rate of occurrence of chronic Chagas disease monitored at the referral outpatient clinic in Pernambuco State, 2016-2018. 


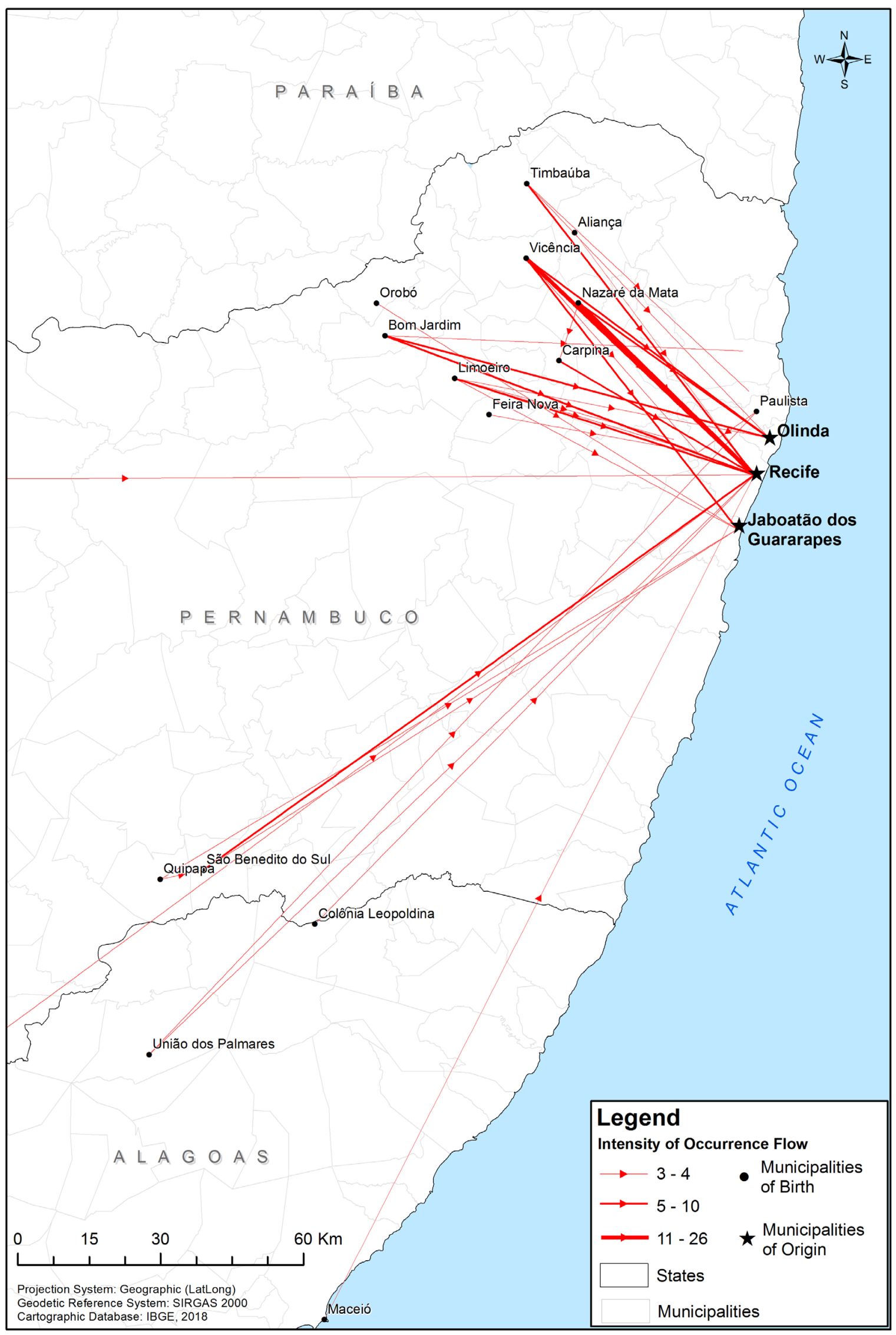

Figure 3 - Flow Map (The birth place/ residence of chronic cases of Chagas disease). 
Overall, 350 deaths were recorded in the SIM; 210 of these occurred in men and 262 in those aged $\geq 60$ years. Most deaths occurred due to chronic disease; $75.5 \%$ were related to heart failure, $12.5 \%$ to digestive system involvement, $2.5 \%$ to the involvement of other organs, and $1 \%$ to nervous system involvement; in $8.5 \%$ of the cases, the clinical form was unspecified (B57).

The annual average mortality associated with Chagas disease was 1.6 per 100,000 inhabitants (standard deviation 2.4). The highest rates were observed in three mesoregions, which showed high standard deviations of mortality (equal to or greater than two standard deviations above the mean) (Figure 4).

\section{DISCUSSION}

Chagas disease, a largely neglected disease, poses a serious public health burden in areas with poor socioeconomic conditions mainly in Latin American countries. In our study, the morbidity and mortality distribution of Chagas disease showed spatial heterogeneity, with the disease identified in all the mesoregions of Pernambuco State. Two mesoregions showed the highest prevalence of both, chronic disease and death, with the main cause of death being heart-related. The nine cases investigated were not confirmed as acute Chagas disease. In 2018, 4,685 cases suspected with acute Chagas disease were reported in Brazil, but only 8.0\% were confirmed T. cruzi etiology ${ }^{19}$. Acute disease appears clinically as a febrile illness, hindering accurate differential diagnoses, as it is also associated with other endemic diseases such as schistosomiasis and visceral leishmaniasis ${ }^{20,21}$.

The chronic disease group in our sample predominantly comprised women $(\mathrm{p}<0.001)$, similar to previous studies in Brazil ${ }^{22-24}$. Over half of women showed a prevalence of the early stages of the disease (A and B1), while stages with ventricular involvement (B2 and $\mathrm{C}$ ) prevailed in men. In the Brazilian cultural context, women seek more health services, while men establish an idea of strength, work provider, with later diagnosis and having cardiovascular diseases as one of the main causes of hospitalization and death ${ }^{25}$. These findings suggest that while the chronic form of the disease is observed more frequently among women, men present with greater disease severity.

Considering the variable age, a predominance of older people was noted in the chronic disease population, with mean age above 60 years, inconsistent with previous findings ${ }^{26}$. This may be attributed to the increased life expectancy and improvements in the treatment of Chagas disease in Brazil ${ }^{6,22}$. Our sample had a prevalence of younger patients in form A (aged less than 60 years) of $32.5 \%$ versus $16.5 \%$ (older than 60 years). Additionally, studies conducted in both, the Northeast ${ }^{27,28}$ and the Southeast ${ }^{22,24}$ regions of Brazil reported a higher prevalence among older people, consistent with our data.

The majority of our chronic disease patients had low education levels, up to U\$209 of family income per month, past housing in mud houses, presence of the vector, and predominance of the vector transmission form, similar to the findings of other studies carried out in Brazil and

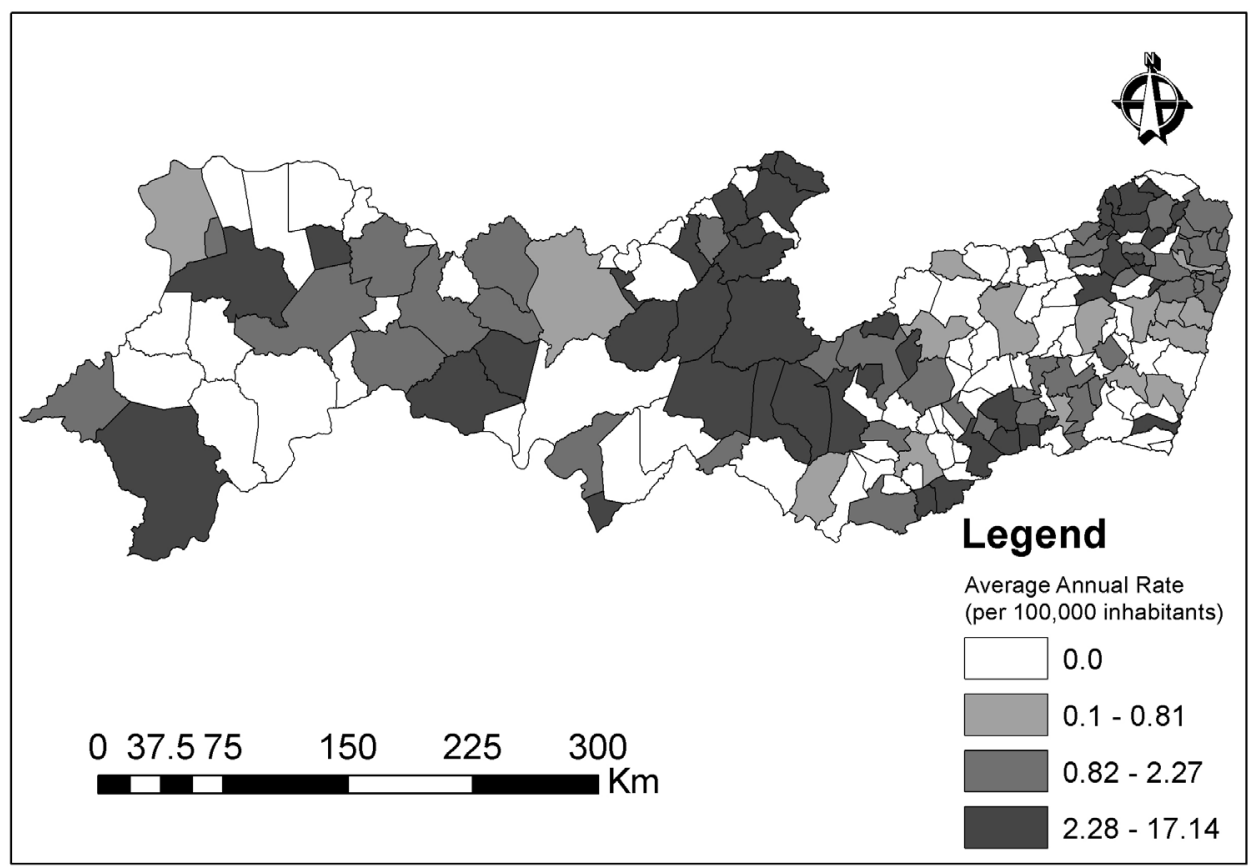

Figure 4 - Map on the mortality rate due to Chagas disease registered in the SIM. Pernambuco State, 2016-2018. 
Mexico $^{22,29}$. Regarding the family income, those with low income levels had higher levels of cardiac impairment $(p<0.001)^{28}$.

Considering comorbidities, the main type was hypertension $(p<0.001)$, as previously demonstrated ${ }^{22}$. Coronary artery disease was also reported $(p<0.001)$. Previous studies demonstrated the presence of microvascular changes in association with Chagas disease, as the disease significantly increases the risk of coronary disease, unlike in the past ${ }^{9,30}$. The occurrence frequency of hypertension and coronary heart disease was higher in patients with cardiac involvement (B and $\mathrm{C}$ ) than in those with form A disease; however, in a previous study performed in Rio de Janeiro ${ }^{22}$ no difference was observed between the clinical forms. This can be explained by the higher prevalence of cardiac involvement with heart failure in our sample, resulting in a higher number of cardiovascular and thromboembolic events.

A high frequency of comorbidities in older people has been previously demonstrated in Ceara ${ }^{27}$, with hypertension as the most commonly cited comorbidity. Older people may be more vulnerable to the development of comorbidities due to the association between aging and cardiovascular changes, and they require a greater degree of health care.

The more prevalent electrocardiographic changes associated with Chagas disease, such as RBBB and LAFB ${ }^{9}$, were observed in over $40 \%$ of the patients in our study. Studies conducted on Brazilian residents and foreigners in Italy and Spain showed the same changes ${ }^{27,28,31,32}$. Heart failure was present in more than $26 \%$ of the patients and the associated unfavourable prognoses led to an increased need for heart transplantation and increased mortality compared to people with other etiologies ${ }^{9,30}$, indicating a higher disease severity in the patients.

Regarding the clinical classification used for the evaluation of severity of chronic Chagas cardiopathy ${ }^{5,33}$, the most prevalent form was B1 followed by C. The higher prevalence of the cardiac form compared to the intermediate form can be explained by the fact that our facility is specialized in the provision of cardiological services, compared to studies that were conducted in other settings such as infectious diseases and tropical medicine institutions ${ }^{22}$.

In our study, the presence of digestive abnormalities such as megacolon and megaesophagus was observed in similar percentages when compared to other Brazilian studies ${ }^{22,27,28}$. Stroke was present in more than $10 \%$ of the patients and was potentially the predominant manifestation associated with embolic events ${ }^{9}$. A higher frequency of these abnormalities was noted in clinical forms with cardiologic involvement than in the indeterminate form $(p=0.001)$. A previous meta-analysis revealed that Chagas disease is associated with a two-fold increase in the risk of stroke ${ }^{34}$.

Our findings revealed the average occurrence rate of chronic Chagas disease, which shows a heterogeneous spatial distribution with clusters in some areas and municipalities exhibiting above-average rates in two mesoregions. The distribution of Chagas disease, a zoonotic disease, is related to social and environmental conditions, as vector transmission occurs predominantly in populations with poor socioeconomic conditions in Latin American countries $^{29,35}$.

The highest rates of chronic Chagas disease were observed in Zona da Mata and Sertao, both mesoregions with a low HDI and it was predominant in rural areas. The municipality with the highest occurrence rate is located in Zona da Mata, with the lowest HDI of the mesoregion ${ }^{11}$. An Argentine study that used geospatial analysis revealed a predominance of vector transmission in rural areas and transition areas with a semiarid climate, housing conditions similar to those noted in our study ${ }^{35}$. In 2012, Zona da Mata presented the lowest numbers and Sertao presented the highest numbers of $T$. brasiliensis infection in the State, due to which it is considered the most important vector in the Northeast region of Brazil. In addition, a significant increase was observed in the prevalence of $P$. lutz $i$ infection with a natural infection rate superior to that associated with the other species evaluated ${ }^{7}$. In Mexico, the occurrence rate of Chagas disease ranged from 1.1 to 4.4/100,000 inhabitants/year ${ }^{36}$; however, the highest rates were observed in rural areas where agriculture was the main occupation and socioeconomic conditions were poorer ${ }^{29,36}$, consistent with our findings.

The disease origin and residence flow map of the population monitored in the outpatient reference service showed that only $14 \%$ of the chronic disease patients presented a number greater than or equal to three network connections, indicating a high origin area diversity, with high values observed in rural Pernambuco and other states in the Northeast region. The Metropolitan Region was the mesoregion with the highest number of inbound Chagas disease cases, owing to the migration of individuals in search of better living conditions. In a Chinese study, this type of map was used for identifying the migration of people with pulmonary tuberculosis ${ }^{37}$. In an oncologic study, this kind of map was employed for the identification of the need for the patient to seek for a specialized health service ${ }^{38}$. In our study, it is likely that the distance between the Sertao region and the reference center also had an impact on the indicators of disease occurrence and mortality due to Chagas disease. 
In 2017, the mortality from Chagas disease in Brazil was 2.2 deaths $/ 100,000$ inhabitants and the rate in Pernambuco State was 1.17 deaths/100,000 inhabitants ${ }^{19}$; the corresponding rate in our study was 1.6 per 100,000 inhabitants. Nevertheless, the municipalities with higher mortality values have also shown the highest rates of chronic disease, with patterns of homogeneity observed in two mesoregions. The morbidity and mortality associated with Chagas disease still exert a significant impact in endemic regions. Therefore, the identification of areas with higher incidence values may allow the identification and implementation of epidemiological and entomological surveillance measures, in addition to the integration of assistance services and decentralisation of specialized services.

This study used information from SIM, SINAN, and medical records from the outpatient clinic for the identification of the epidemiological status of Chagas disease in endemic areas. While interpreting the results, it should be taken into account that this study presents limitations due to the use of secondary data, which may lead to inconsistency in the quantity and quality of processed information. However, to minimize these limitations, duplication, incompleteness, and inconsistency in the notification were analyzed by cleaning the database. The Chagas disease prevalence and mortality may be underestimated due to the lack of diagnoses and notifications of acute and chronic cases in the SINAN and also to the lack of investigation on the underlying cause of death. The population residing in remote areas that have less access to specialized care can influence the underreporting of cases and deaths. Nevertheless, we were able to identify population groups in endemic areas with strong indicators of chronic disease and deaths in these settings.

\section{CONCLUSION}

In conclusion, the present study revealed that the two areas with the highest rates of chronic disease also had the highest rates of death, with the main cause of death being heart-related. Future studies are needed to analyze the association of the disease with the vectors in these mesoregions to indicate the risk of transmission or risk of exposure.

These findings highlight the need for specialized services and decentralisation of cardiology centers, as well as improvements in the policies and actions aimed at areas with the largest number of deaths and cases to prevent deaths from Chagas disease. This highlights the need for more specialized services in areas with the highest disease burden to avoid delay in the patients' care.

\section{CONFLICT OF INTERESTS}

The authors report no conflicts of interest. The authors alone are responsible for the content and writing of this article.

\section{FUNDING}

This study was financed in part by the Coordenação de Aperfeiçoamento de Pessoal de Nível Superior (CAPES), Brazil, Finance Code 001.

\section{REFERENCES}

1. World Health Organization. Chagas disease (American trypanosomiasis). [cited $2021 \mathrm{Dec} 2$ ]. Available from: https:// www.who.int/health-topics/chagas-disease\#tab=tab_1

2. Gorla DE, Xiao-Nong Z, Diotaiuti L, Khoa PT, Waleckx E, Souza RC, et al. Different profiles and epidemiological scenarios: past, present and future. Mem Inst Oswaldo Cruz. 2021;116:e200409.

3. Santos E, Menezes Falcão L. Chagas cardiomyopathy and heart failure: from epidemiology to treatment. Rev Port Cardiol. 2020;39:279-89.

4. Martins-Melo FR, Ramos Jr AN, Alencar CH, Heukelbach J. Mortality from neglected tropical diseases in Brazil, 20002011. Bull World Health Organ. 2016;94:103-10.

5. Andrade JP, Marin-Neto JA, Paola AA, Vilas-Boas F, Oliveira GM, Bacal F, et al. I Latin American Guideline for the Diagnosis and Treatment of Chagas' Heart Disease. Arq Bras Cardiol. 2011;97 Suppl 3:1-48.

6. Martins-Melo FR, Ramos Jr AN, Alencar CH, Heukelbach J. Prevalence of Chagas disease in Brazil: a systematic review and meta-analysis. Acta Trop. 2014;130:167-74.

7. Silva MB, Barreto AV, Silva HA, Galvão C, Rocha D, Jurberg $\mathrm{J}$, et al. Synanthropic triatomines (Hemiptera, Reduviidae) in the state of Pernambuco, Brazil: geographical distribution and natural Trypanosoma infection rates between 2006 and 2007. Rev Soc Bras Med Trop. 2012;45:60-5.

8. Pérez-Molina JA, Molina I. Chagas disease. Lancet. 2018;391:82-94.

9. Bocchi EA, Bestetti RB, Scanavacca MI, Cunha Neto E, Issa VS. Chronic Chagas heart disease management. J Am Coll Cardiol. 2017;70:1510-24.

10. Duarte LF, Flórez O, Rincón G, González CI. Comparison of seven diagnostic tests to detect Trypanosoma cruzi infection in patients in chronic phase of Chagas disease. Colomb Med (Cali). 2014;45:61-6.

11. Instituto Brasileiro de Geografia e Estatística. Estimativas da população. [cited 2021 Dec 2]. Available from: https:// www.ibge.gov.br/estatisticas/sociais/populacao/9103-\%20 estimativas-de-populacao.html $?=\& \mathrm{t}=$ downloads 
12. Pinto LF, Freitas MP, Figueiredo AW. National information and population survey systems: selected contributions from the Ministry of Health and the IBGE for analysis of Brazilian state capitals over the past 30 years. Cien Saude Coletiva. 2018;23:1859-70.

13. Brasil. Ministério da Saúde. SINAN: Sistema de Informação de Agravos de Notificação. [cited 2021 Dec 2]. Available from: https://portalsinan.saude.gov.br/

14. Brasil. Ministério da Saúde. Gabinete do Ministro. Portaria $\mathrm{N}^{\circ}$ 264, de 17 de fevereiro de 2020. Altera a Portaria de Consolidação $n^{\circ}$ 4/GM/MS, de 28 de setembro de 2017, para incluir a doença de Chagas crônica, na Lista Nacional de Notificação Compulsória de doenças, agravos e eventos de saúde pública nos serviços de saúde públicos e privados em todo o território nacional. Diário Oficial da União, Brasília, 19 fev. 2020, Seção 1:97. [cited 2021 Dec 2]. Available from: http://portalsinan.saude.gov.br/images/documentos/ Legislacoes/Portaria_N_264_17_FEVEREIRO_2020.pdf

15. Martins SM, Moura CB, Cavalcanti MG, Carrazzone CF, Medeiros CA, Oliveira Junior W. Beyond the disease: history of the House for Patients with Chagas Disease and Heart Failure of Pernambuco. ABC Heart Fail Cardiomyop. 2021;1:15-26.

16. World Health Organization. Chagas disease in Latin America: an epidemiological update based on 2010 estimates. Wkly Epidemiol Rec. 2015;90:33-43.

17. Brasil. Ministério da Saúde. Secretaria de Vigilância em Saúde. Sistema de Informações sobre Mortalidade (SIM). [cited 2021 Dec 2]. Available from: https://www.gov.br/saude/pt-br/ composicao/vigilancia-em-saude-svs/sistemas-de-informacao/ sistema-de-informacoes-sobre-mortalidade-sim

18. Rabino GA, Occelli S. Understanding spatial structure from network data: theoretical considerations and applications. Cybergeo. 1997:29.

19. Brasil. Ministerio da Saúde. Secretaria de Vigilância em Saúde. Panorama da doença de Chagas no Brasil. Bol Epidemiol. 2019;50:1-14. [cited 2021 Dec 2]. Available from: https:// antigo.saude.gov.br/images/pdf/2019/novembro/29/Boletimepidemiologico-SVS-36-interativo.pdf

20. Nunes MC, Guimarães Júnior MH, Diamantino AC, Gelape CL, Ferrari TC. Cardiac manifestations of parasitic diseases. Heart. 2017;103:651-8.

21. Sangenito LS, Silva Santos V, d'Avila-Levy CM, Branquinha MH, Souza dos Santos AL, Oliveira SS. Leishmaniasis and Chagas disease: neglected tropical diseases: treatment updates. Curr Top Med Chem. 2019;19:174-7.

22. Vizzoni AG, Varela MC, Sangenis LH, Hasslocher-Moreno AM, Brasil PE, Saraiva RM. Ageing with Chagas disease: an overview of an urban Brazilian cohort in Rio de Janeiro. Parasit Vectors. 2018;11:354.

23. Gasparim AZ, Fontes CE, Rossoni DF, Toledo MJ. Epidemiological and clinical profile of patients with chagas disease in the central-north area of Paraná, Southern Brazil. Rev Soc Bras Med Trop. 2018;51:225-30.

24. Bruscato A, Pereira MB, Archilia MD, Teodoro TM, Almeida EA, Martins LC, et al. Using a chagas disease hospital database: a clinical and epidemiological patient profile. Rev Soc Bras Med Trop. 2018;51:831-5.

25. Oliveira GM, Mendonça RM, Medeiros CA, Oliveira Júnior W, Carrazzone C, Moura CB, et al. A integração entre a vigilância em saúde e o ambulatório de referência na assistência ao paciente acometido por doença de Chagas e o perfil nesse serviço. In: Melo AL, Albuquerque LC, Reis YA, Silva IM, Cazarin G, Andrade AR, organizadores. Saúde Pernambuco: reflexões, evidências e experiências da vigilância em saúde. Recife: Secretaria de Saúde; 2019. p.347-66.

26. Simões TC, Borges LF, Assis AC, Silva MV, Santos J, Meira KC. Chagas disease mortality in Brazil : a Bayesian analysis of age-period-cohort effects and forecasts for two decades. PLoS Negl Trop Dis. 2018;12:e0006798.

27. Pereira LS, Freitas EC, Fidalgo AS, Andrade MC, Cândido DS, Silva Filho JD, et al. Clinical and epidemiological profile of elderly patients with Chagas disease followed between 2005 2013 by pharmaceutical care service in Ceará State, Northeastern Brazil. Rev Inst Med Trop Sao Paulo. 2015;57:145-52.

28. Glass IR, Santos AD, Varjão AE, Costa IS, Correia D, Silva AM. Clinical and epidemiological characteristics of Chagas disease in an endemic area of Sergipe State, Brazil. Rev Soc Bras Med Trop. 2018;51:660-4.

29. Ibáñez-Cervantes G, León-Garciá G, Castro-Escarpulli G, Mancilla-Ramírez J, Victoria-Acosta G, Curenõ-Diáz MA, et al. Evolution of incidence and geographical distribution of Chagas disease in Mexico during a decade (2007-2016). Epidemiol Infect. 2018;147:e41.

30. Shen L, Ramires F, Martinez F, Bodanese LC, Echeverría LE, Gómez EA. Contemporary characteristics and outcomes in Chagasic heart failure compared with other nonischemic and ischemic cardiomyopathy. Circ Heart Fail. 2017;10:e004361.

31. Repetto EC, Zachariah R, Kumar A, Angheben A, Gobbi F, Anselmi M, et al. Neglect of a neglected disease in Italy: the challenge of access-to-care for Chagas disease in Bergamo area. PLoS Negl Trop Dis. 2015;9:e004103.

32. Sánchez-Montalvá A, Salvador F, Rodríguez-Palomares J, Sulleiro E, Sao-Avilés A, Roure S, et al. Chagas cardiomyopathy: usefulness of EKG and echocardiogram in a non-endemic country. PLoS One. 2016;11:e0157597.

33. Nunes MC, Beaton A, Acquatella H, Bern C, Bolger AF, Echeverría LE, et al. Chagas cardiomyopathy: an update of current clinical knowledge and management: a scientific statement from the American Heart Association. Circulation. 2018;138:e169-209.

34. Cardoso RN, Macedo FY, Garcia MN, Garcia DC, Benjo AM, Aguilar D, et al. Chagas cardiomyopathy is associated with 
higher incidence of stroke: a meta-analysis of observational studies. J Card Fail. 2014;20:931-8.

35. Weinberg D, Lanfri M, Scavuzzo CM, Abril M, Lanfri S. Evaluation and planning of chagas control activities using geospatial tools. Geospat Health. 2019;14:229-38.

36. Arnal A, Waleckx E, Rico-Chávez O, Herrera C, Dumonteil E. Estimating the current burden of Chagas disease in Mexico: a systematic review of epidemiological surveys from 2006 to 2017. PLoS Negl Trop Dis. 2019;13:e0006859.
37. Liao WB, Ju K, Gao YM, Pan J. The association between internal migration and pulmonary tuberculosis in China, 2005-2015: a spatial analysis. Infect Dis Poverty. 2020;9:5.

38. Saldanha RF, Xavier DR, Carnavalli KM, Lerner K, Barcellos C. Estudo de análise de rede do fluxo de pacientes de câncer de mama no Brasil entre 2014 e 2016. Cad Saude Publica. 2019;35:e00090918. 